\title{
A experiência da toxicomania e da reincidência a partir da fala dos toxicômanos ${ }^{1}$
}

\author{
The experience of the toxicomania and reincidence \\ through to toxicomaniacs' speech
}

\author{
Clayton Ezequiel dos SANTOS ${ }^{2}$ \\ Abílio da COSTA-ROSA ${ }^{3}$
}

\begin{abstract}
Resumo
Este estudo teve como objetivo examinar o fenômeno da toxicomania e sua reincidência a partir da fala dos toxicômanos. Foi realizado em instituição especializada no tratamento da dependência química e problemas relacionados ao uso de álcool e outras drogas, contando com dados do acompanhamento de onze sujeitos. Utilizou-se o referencial teórico psicanalítico para a escuta de indivíduos em situação de toxicomania, com o dispositivo das entrevistas preliminares, dentro do referencial da "clínica da urgência" em psicanálise. Os resultados do trabalho de escuta e da reflexão apontaram uma série de características psicológicas dos indivíduos estudados de clara relevância para o planejamento de estratégias individuais ou coletivas de atenção ao problema. Destacamos a hipótese de duas modalidades de toxicomania relacionadas com as formas particulares da subjetividade em que ocorre. A questão da reincidência na toxicomania aparece como um falso problema para os sujeitos, que demonstraram que a desintoxicação, concomitante à abstinência e provocada pela internação, é somente um momento de privação, simultaneamente necessária e forçada, do gozo propiciado pela droga. Finda a internação segue-se, geralmente, um novo período de uso. A aceitação da abstinência não significa que os sujeitos fazem uma renúncia, correlata, ao desejo pela droga. É apenas uma parada provavelmente ligada à menor tolerância psíquica à modalidade de gozo em ação na toxicomania, um gozo capaz de confrontar o sujeito com a morte. A abstinência forçada, como estratégia da política pública de saúde, presente no tratamento comum da toxicomania, mostrou conseqüências altamente negativas para o resultado do tratamento, parecendo indicar a necessidade de sua revisão urgente. Procurou-se problematizar a questão da abertura à dimensão subjetiva da experiência dos toxicômanos como estratégia capaz de interferir na trajetória dos sujeitos na relação com as drogas a partir do momento em que buscam ajuda.
\end{abstract}

Unitermos: psicanálise; reincidência; saúde coletiva; toxicomania.

\begin{abstract}
This study had examined the toxicomania phenomenon and its reincidence from toxicomaniac's speech. This study has been performed in a specialized unitforchemical dependence treatment and troubles about alcohol ingestion and other drugs. The study is based on the clinical data from eleven subjects. The paper, performed within the theoretical psychoanalytical perspective was based on drug addiction accounts, whose preliminary interviews wereembased on psychoanalysis' "urgency clinic's" parameters. Thelistening and reflection results indicated many psychological characteristics which are relevantfor planning carestrategies concerning about individualistic and collective problems.
\end{abstract}

$\boldsymbol{\nabla \nabla \nabla v}$

1 Artigo elaborado a partir da dissertação de C.E. SANTOS, intitulada "A reincidência na drogadicção, a partir da visão do adicto". Curso de Pós-Graduação Psicologia e Sociedade, Universidade Estadual Paulista de Assis, 2005.

2 Universidade Estadual Paulista, Programa de Pós-Graduação, Curso de Psicologia. Assis, SP, Brasil.

3 Universidade Estadual Paulista, Faculdade de Ciências e Letras, Departamento de Psicologia Clínica. Av. Dom Antônio, 2.100, Parque Universitário, 19806-900, Assis, SP, Brasil. Correspondência para/Correspondence to: A. COSTA-ROSA. E-mail: <abiliocr@assis.unesp.br>. 
We distinguished two kinds of toxicomania related to the subjectivity types. The reincidence issue is a false dilemma and detoxification, along abstinence and also provoked by hospitalization is only a moment of drug deprivation that will be propably followed by a new period of drug use. Abstinence does not mean that the subjects have renounced to their drug willing. It is only an interruption correspondent to the low body tolerance in regard to the toxicomania mental fight, that follows the addicted person until death. The forced abstinence, as a public health policy and strategy, present in the toxicomania ordinary treatment, showed highly negative consequences, and need urgently to be revised. This study had tried to put the toxicomaniacs' unique experience into discussion as a intervention strategy for the these subjects' addiction itinerary concerning the moment they search for help.

Uniterms: psychoanalysis; recurrence; public health; toxicomania.

Neste artigo são abordados alguns aspectos pouco frisados pelos estudiosos da toxicomania e pela sociedade em geral: a experiência da toxicomania a partir da fala dos próprios sujeitos.

Nos estudos já realizados sobre o tema, é consensual a dificuldade de trabalhar a questão das drogas sob um ponto de vista unilateral (Batista \& Inem, 1997). Mesmo quando a questão é o usuário de drogas, também há parcialidade, pois a tendência é focalizar o olhar nele como protagonista principal do rompimento com a norma, associando-o à delinqüência e ao narcotráfico. Antes de tudo é necessário lembrar que nossa sociedade é uma voraz consumidora de drogas, desde o consumo mais banalizado, como o cigarro e o café, passando pelos diferentes tipos de drogas consideradas ilícitas, até o uso de álcool, que permanece como o mais fecundo objeto de prazer quando o assunto é festejar. Os novos objetos da ciência que trazem a promessa de felicidade, os psicofármacos, também vêm alcançando grande destaque. Sua utilização, inicialmente proposta para o tratamento das "doenças mentais" através da prescrição médica, compõe um novo cenário do uso ilícito, ou pouco discriminado, de drogas lícitas.

A problemática da drogadicção vem ganhando espaço nas grandes discussões dos mais variados segmentos do conhecimento. Porém a visibilidade que se dá a essa temática nos meios de comunicação de massa vem associada, constantemente, aos grandes índices de violência, supostamente "provocados" pelo consumo de droga. Dificilmente se escapa ao clichê que vê a droga e os drogados como um mal intrínseco que espreita indiscriminadamente os filhos indefesos das boas famílias. A imprensa, e principalmente a televisão, vem trazendo, para dentro da casa dos brasileiros, imagens do pavor "gerado" pelos efeitos da queda no submundo das drogas. Nota-se um esforço na especulação dos motivos que levam as pessoas a usar drogas: más influências, lazer, curiosidade, sofrimento e perdas ao longo da vida.

Recentemente as toxicomanias, ao lado do alcoolismo, vêm adquirindo estatuto de problema de saúde coletiva. O Ministério da Saúde tem incluído em suas prioridades a criação de dispositivos institucionais voltados especificamente para a atenção às problemáticas relacionadas ao alcoolismo e à toxicomania: Centros de Atenção Psicossocial - álcool e drogas - CAPSad (Ministério da Saúde, 2004).

A relação dos sujeitos com a droga não é linear, pois pode compreender várias categorias, como uso recreativo, abusivo e a adicção. Somente essa última nos interessa neste trabalho, por atingir uma situação limite que implica a "escravidão" do indivíduo diante da droga, que se torna o objeto de um prazer sentido como necessidade, e que assume o comando das ações do sujeito.

Vejamos, então, em maior detalhe esse conceito de adicção. Primeiramente, é importante destacar que a palavra "adicção"é inexistente na língua portuguesa e só encontramos aproximações do seu significado quando nos reportamos ao adjetivo adicto, que quer dizer afeiçoado, dedicado, apegado ou mesmo dependente. A adicção, segundo Gurfinkel (1995), deve ser caracterizada muito mais como um modo de funcionamento psíquico na relação com o objeto do que propriamente como uma qualidade intrínseca referida ao sujeito que se droga. Desse modo, o funcionamento adicto pode dar-se por meio de objetos diferenciadose em contextos diversos. Portanto muitos podem ser os objetos de uma adicção, desde a comida até a droga, passando por pessoas do mesmo gênero ou do oposto, partes específicas do corpo, a informática, a televisão, o jogo, enfim, qualquer objeto da "sociedade de consumo" passível de apropriação compulsiva. A compulsão por consumir drogas seria apenas mais um tipo de ação 
impulsiva presente num modo humano de agir, cuja característica essencial é a falta de limite, a ser entendida como perturbação da intermediação simbólica da relação do sujeito com seus objetos de gozo.

Neste estudo é de interesse especificar um tipo especial de uso de drogas e um modo particular de adicção: trata-se da toxicomania (Garfinkel, 1995).

O que especifica o uso de drogas como toxicomania? Em primeiro lugar, diante do objeto com o qual está estabelecido o vínculo de prazer, o sujeito toxicômano mostra-se impotente quanto à possibilidade de administrar seu uso. Na presença do objeto-droga, o toxicômano se defronta com sua incapacidade de pensar, reagindo com uma ação compulsiva, correspondente de uma tensão que parece ser vivenciada como impossível de baixar por outros meios. Parecendo ser comandado pelo objeto, o indivíduo fracassa, sobretudo, quanto à capacidade de utilizar a linguagem e o pensamento como meios de ponderação e de dar significação ao impulso desencadeado. Assim, a falta de prazer pode reaparecer logo após o alívio da tensão proporcionado pelo uso da droga. Sua ingestão demonstra, na prática, ser pouco eficaz para fazer frente às necessidades e desejos que o sujeito busca resolver por meio da utilização compulsiva. Diante dessa falta de prazer, e também por causa dela, o ciclo compulsivo recomeça.

Para melhor situar uma discussão em torno do fenômeno da toxicomania, entendendo-a como uma forma particular de adicção, recorreremos à teoria psicanalítica a fim de tentar especificar a modalidade de gozo aí presente. Segundo Valas (2001), é a partir do entendimento de que o inconsciente é estruturado como linguagem, e de que o ser humano é um ser de linguagem, portanto de sentido, que podemos compreender que a causação significante do gozo pode produzir diferentes modalidades de emergência deste, na realidade do sujeito, dependendo das particularidades da sua entrada no significante e na linguagem. Em suma, dependendo de como se deu o processo de sua constituição subjetiva.

A psicanálise define várias modalidades de gozo dependentes dos modos de entrada do sujeito no simbólico. Dessas formas de gozo é necessário destacar duas. A modalidade de gozo do Outro, em que devemos entender que o Outro designa o próprio corpo, e na qual está em jogo uma forma do gozo que não passa pela linguagem. Ou seja, trata-se de um gozo fora da mediação do simbólico. Esse modo de gozo é vivenciado como um acontecimento que suprime a palavra e retira a possibilidade de simbolização daquilo que é experimentado como falta. Somente o objeto-droga é reconhecido como o complemento necessário, criando um ciclo que perpetua a crença no gozo obtido apenas diretamente no próprio corpo. Por esquivar-se ao simbólico, podemos dizer que o corpo em ação, neste caso, é o corpo como "corpotodo", objeto de um "gozo todo" (não localizado e não simbolizado). O gozo do corpo, que neste caso chamaremos simplesmente gozo da droga, parece estar relacionado com o retorno, podemos dizer real, da mítica experiência primordial de gozo, que permaneceu até o momento do primeiro uso em estado de marca mnêmica não simbolizada para o futuro toxicômano (Lima, 1998).

Destacamos também a modalidade que a psicanálise denomina gozo fálico, que é o gozo ligado à linguagem, à mediação do simbólico, um gozo acessível ao sujeito como localizado em partes do corpo, podendo manifestar-se também como gozo da palavra e da linguagem. O gozo fálico supõe a cifragem, a simbolização do gozo corporal pelo significante através dos traços mnêmicos das experiências cruciais constitutivas do aparelho psíquico. O gozo fálico está associado à modalidade de constituição subjetiva por recalcamento, estando estreitamente ligado aos ideais socioculturais. Manifesta-se, também, nas formações inconscientes do sujeito: chistes, lapsos, sintomas, esquecimentos, sonhos.

Esclarecidas essas duas modalidades de gozo, podemos conceber a hipótese da toxicomania como uma forma de relação com o gozo em que, fantasiosamente, se reporia o gozo imediato e total (mítico), que a entrada no universo da linguagem teria expropriado. Daí que tal gozo seja fortemente marcado com as características do gozo do Outro, ou seja, o gozo do corpo em que o sujeito evita a intermediação da linguagem, e só the interessa gozar, provocando um curto-circuito do simbólico. Quando falamos do toxicômano estamos falando de uma figura de gozo que não se submete aos valores ditos fálicos, que definem o gozo generalizado da nossa civilização (gozo 
sexual, gozo sublimado na relação com a procriação, o trabalho e a cultura). O toxicômano, então, pode ser visto como um sujeito dominado pelo seu gozo, um gozo do corpo como todo, ainda mais radical e compulsivo que o gozo do consumista, do bulímico e do viciado em azar, nas variadas formas de jogo (Souza, 2003).

Podemos, então, definir o sujeito toxicômano como aquele que tentaria, por meio da droga, fugir das determinações impostas pelas exigências e pelos ideais sociais (também ditos fálicos), com um gozo do corpo que, se não é limitado pela intermediação da linguagem e através da simbolização dos limites, só pode ser limitado pela morte; daí a propensão conhecida dos toxicômanos aos riscos da overdose.

Na toxicomania o modo comum de relação com o gozo típico do sintoma (gozo fálico) é abolido, surgindo um vazio quanto à capacidade desejante. 0 sujeito está sob o domínio do gozo do Outro numa forma paroxística, gozo mortífero vivenciado como necessidade radical, que só pode ser preenchido pela droga como objeto concreto. Assim, pode-se dizer que, para o toxicômano, a droga substitui o sintoma, propiciando ao sujeito um acesso direto ao gozo. Sem passar pelo sentido simbólico, na experiência com a droga o toxicômano parece estar funcionando no registro do real e do imaginário, que se evidencia por um lado na forma do gozo: direto no próprio corpo; e por outro, na forma tautológica como expressa sua identidade: "sou toxicômano". Seus relatos sobre a experiência da abstinência nos dão, de forma candente, a contrapartida da angústia que preside a esse modo de solução psíquica da relação com o objeto.

A contribuição da psicanálise para a compreensão da toxicomania e para a realização do tratamento pode ser fundamental. Estando fora do princípio médico "doença-cura", ela pode propor ao toxicômano um caminho que lhe permita reinstaurar a divisão subjetiva, incidindo diretamente em uma de suas importantes características psíquicas: o toxicômano entende que só ele detém o saber da experiência de drogar-se (nada quer saber sobre outros gozos, e sobre esse ninguém sabe mais do que ele próprio), por isso não faz suposição de saber no Outro, que seria o ponto de partida para a possibilidade de vínculo transferencial e para a impli490 cação subjetiva em sua história particular. Essa realo- cação do sujeito no campo da linguagem e da subjetividade, que parece essencial à possibilidade de mudar a relação de extrema dependência com a droga, só pode ser conseguida com uma oferta compatível de possibilidades de transferência. Alguns exemplos de como esse processo pode ser iniciado são oferecidos pelo trabalho que forneceu os dados para esta reflexão, como veremos adiante.

O sujeito da toxicomania insiste em só representar-se como ser, no lugar de indivíduo, e ausente da performance desejante suposta pela divisão subjetiva. Como se fosse um "eu" fazendo do seu corpo um lugar da experiência e do prazer. Sua experiência aparece tão profundamente singular, que ele insiste em que ninguém, além dele, sabe o que acontece. Em parte não temos por que discordar. Nesse contexto, a psicanálise visa estabelecer uma relação intersubjetiva, um novo laço social, capaz de possibilitar-lhe transitar da experiência da droga para suas experiências de sujeito. Trata-se de introduzi-lo na linguagem, no gozo do significante, com a hipótese de que, através das demandas trazidas, possam ser criados por ele novos sentidos para o ato de drogar-se. Espera-se que, a partir disso, o sujeito possa conduzir-se à via do desejo, marcando sua relação com formas do gozo que suportem a intermediação, a espera e a diversificação. Trabalha-se a partir da hipótese de que a oferta de escuta, dando a palavra ao sujeito, faz com que a passagem pela intermediação significante da linguagem funcione como uma espécie de exercício num registro de gozo capaz de competir com o gozo da droga.

Pode-se acrescentar que nesse modo de relação do sujeito com o significante espera-se uma espécie de cifragem do gozo corporal pela linguagem, que pode permitir lidar com os impulsos de usar drogas, de modo a poder responder a eles atenuando a compulsão. Está implícita a idéia de que há gozo, para o sujeito, na produção de sentido novo; e que essa experiência subjetiva pode funcionar como desencadeadora de outras na mesma direção.

Dessa maneira, ao contrário da medicina e da psiquiatria que colocam a toxicomania no lugar de doença, a psicanálise faz outra leitura, entendendo que se trata de um fenômeno complexo, cuja dimensão psíquica pode inscrever-se de modo contingente na vida cotidiana dos indivíduos, portanto, passível de ser revertido. 
Retomando nosso objetivo de circunscrever teoricamente a toxicomania, acrescentamos que numa determinada vertente da psicanálise diz-se que ela não é uma estrutura porque não recorre ao registro do simbólico; não é um sintoma, porque rompe com o gozo fálico, e não pode ser reduzida a uma perversão porque não é mediada pela fantasia (Laurent,1995). Ao pensarmos a estruturação subjetiva do ponto de vista freudiano e lacaniano, é possível afirmar genericamente que o toxicômano é um sujeito cuja modalidade de constituição está no âmbito da renegação/Nerleugnung (Freud, 1927). Outras vezes ainda se fala em estatuto perverso, só que estruturalmente mais precário, na medida em que ficou prejudicado por não ter o recurso da fantasia como intermediador na relação com o objeto de gozo. Nos sujeitos da renegação em geral, o recurso psíquico da fantasia parece funcionar como pacificador de gozo, ao passo que no toxicômano a falta dela marca uma relação com a droga que o leva a um gozo encarniçado, beirando o mortífero (Laureant, 1995).

Entretanto a clínica tem demonstrado que a toxicomania não escolhe estruturação subjetiva. A ela se aplica positivamente o adágio da loucura: é toxicômano quem quer! Nesse sentido, uma outra vertente da psicanálise considera que o sujeito toxicômano é constituído como qualquer outro dentro das diversas possibilidades contingentes de entrada do sujeito na relação com a linguagem como campo do simbólico, ou seja, pode ser constituído por foraclusão/Vewerfunf (Lacan, 1985), por renegação/Verleugnung (Freud, 1927) ou por recalcamento/Verdrängung (Freud, 1915). Cada uma dessas modalidades de constituição determina um modo de relação com o significante e com o gozo. Essa abordagem entende que não existem pontos fracos no processo de subjetivação, capazes de deixar abertas as brechas no funcionamento do sujeito, por onde a droga poderia incidir seletivamente (Nogueira Filho, 1989).

O importante a registrar é que o campo se encontra aberto à pesquisa, e que já se pode encontrar várias hipóteses tentando compreender o fenômeno na sua dimensão subjetiva (Bentes \& Gomes, 1998; Melman, 1992; Olievenstein, 1991; Santiago, 2001), a par das dimensões social e "orgânica".
Este estudo situou-se na perspectiva de que uma compreensão interdisciplinar é mais adequada para dar conta do fenômeno, dada sua complexidade e o momento de sua pesquisa (Batista \& Inen, 1997). Nesse sentido, a nossa modesta contribuição pretende considerar os pontos de vista da psicanálise de Freud e Lacan.

Nossa hipótese é que há modalidades diferenciais de relação toxicomaníaca, embora em todos os casos se trate de toxicomania. Veremos até que ponto nossos dados nos fornecem elementos para reflexão nessa direção. Essas modalidades diferenciais decorrerão justamente da base subjetiva dada pelo processo que originou a constituição de cada sujeito particular e suas conseqüências, em termos das vicissitudes com que tal processo se consolidou. Conforme se trate de recalcamento, foraclusão ou renegação serão, por hipótese, diferentes essas vicissitudes, e delas dependerão as maiores ou menores fragilidades da relação objetal dos sujeitos, assim como as modalidades do sentido e do gozo buscados.

A literatura disponível nos indica, nesta direção, que no recalcamento as drogas comumente entram a serviço da liberação superegóica e do engrandecimento narcísico, sendo, portanto, um meio para outros fins como ocorre especificamente no alcoolismo (Melman, 1992). Na foraclusão tem-se constatado seu uso numa tentativa de fazer barreira ao gozo (angustiante) que ameaça invadir a realidade do indivíduo, impedindo ou protelando um desencadeamento psicótico (Beneti, 1998). Nesses casos a droga estaria sendo utilizada como "suplência química", com função tamponadora4 ${ }^{4}$ tal qual a solução medicamentosa da psiquiatria, não chegando a constituir, portanto, uma relação toxicômana - nosso estudo não encontrou sujeitos nessa situação. Finalmente, na renegação teríamos a droga associada a um funcionamento subjetivo em que o gozo tem consistência real, o gozo do corpo. A especificidade dessa relação com a droga estaria associada a uma pendência no processo de subjetivação primária em que, por algum motivo, teriam ficado não realizados aspectos da passagem dos traços mnêmicos de gozo aos traços mnêmicos de significante, deixando aberta uma

จे

4 Faz-se uma diferenciação importante entre tamponamento e estabilização psíquica, sendo o primeiro apenas uma forma transitória de estancar o sofrimento, geralmente através de meios químicos; suspensos esses meios, por alguma razão, o sofrimento se reinstala. A estabilização supõe um trabalho psíquico de geração de sentido capaz de permitir um reposicionamento do sujeito. 
fragilidade passível de se manifestar na experiência concreta do sujeito: é como se a experiência de drogar-se evocasse a presença real de um gozo inesquecível que deve, a partir do primeiro encontro com a droga, ser compulsivamente comemorado (Lima, 1998).

A experiência clínica tem nos indicado também que, destas possibilidades, a terceira parece ser a que constitui a forma de toxicomania em que se torna mais difícil o questionamento ou a renúncia, pelo sujeito, à forma de gozo experimentado com as drogas. Nesses casos parece mais difícil o surgimento das demandas de interlocução, não sendo incomum que os indivíduos caminhem até à morte sem chegarem a formular qualquer pedido de ajuda.

Por outro lado, a utilização da droga com função narcísica, liberadora, e mesmo iniciada como experiência hedonista, parece ser o tipo mais comum que procura ajuda não só nas instituições do saber oficial, mas também, como sabemos, numa série de instituições místico-religiosas e nos Narcóticos Anônimos (NA). É nessa circunstância subjetiva que se costuma contabilizar alguns sucessos, basicamente concebidos como saídas radicais dos indivíduos da droga, no caso das práticas místico-religiosas (Mariz, 1994), e como interrupções e retornos repetidos, no caso da psiquiatria (Passos, 1997). As ofertas de interlocução fundadas na psicanálise ainda são praticamente inexistentes nas instituições públicas especializadas, recém-implantadas no país pelo Ministério da Saúde, embora elas sejam fundadas no ideário da interdisciplinaridade, intersetorialidade, associadas a estratégias de "redução de danos", e dentro da política oficial da Atenção Psicossocial em implantação e desenvolvimento no país (Ministério da Saúde, 2004; Nogueira Filho, 1999).

Neste artigo pretendemos apresentar e analisar os "dados" colhidos como desdobramento de um trabalho de escuta de um conjunto de indivíduos diagnosticados como toxicômanos, internados em uma instituição pública especializada na atenção às queixas relacionadas à toxicomania e ao alcoolismo. Esses dados foram produzidos na situação inicial da psicoterapia, no dispositivo das entrevistas preliminares em psicanálise. Nossa abordagem desse material tomou como parâmetros dois grandes temas: a experiência da toxicomania e a experiência de reincidência a partir da 492 fala espontânea dos sujeitos.

\section{Método}

O estudo foi realizado em uma instituição especializada (Núcleo de Atenção à Dependência Química - NADeQ, com características hospitalares) para tratamento da dependência química e problemas relacionados ao uso de álcool e outras drogas. Ouvimos um conjunto de usuários de crack e de cocaína, com histórico de tentativa de abandono do uso e posterior retomada, seguida de pedido de reinternação (reincidência), a partir da oferta de escuta psicoterapêutica. Os "dados" de onze sujeitos foram considerados para a reflexão, por serem aqueles que mais persistiram na aceitação dessa oferta de escuta. Esses onze sujeitos estiveram presentes em entrevistas individuais que variaram de três a seis, e um que chegou a configurar uma seqüência de psicoterapia. É importante esclarecer que a estada deles na instituição se dá por períodos curtos, de aproximadamente 15 dias, em média, que é o tempo da desintoxicação. Essa informação pode redimensionar o valor dessas seqüências de escuta em que o sujeito sentia vontade de falar sobre sua experiência subjetiva. Também é oportuno esclarecer que ao saírem do NADeQ eram encaminhados para uma continuidade de tratamento ambulatorial, o que mais comumente não era efetivado (dados de observação).

A pesquisa em psicanálise pressupõe a reflexão a partir de um dado "material clínico" obtido em uma intercessão que não definia o campo como de pesquisa. É no material resultante desse trabalho que o pesquisador, num momento posterior, se detém. Ele se debruça sobre esse material com familiaridade extrema, pois foi constituído numa relação de escuta composta por psicoterapeuta e os sujeitos no momento da intercessão. Portanto nossa reflexão tem como referente uma experiência realizada como profissional da saúde pública que se fundamenta na psicanálise como referencial teórico para a "análise dos dados" dessa prática. Mas que, sobretudo, utiliza o método psica-nalítico, que produziu esta teoria, como ferramenta para o trabalho realizado, de que derivam os dados.

Na situação dada, considerou-se pertinente a oferta, aos indivíduos, de entrevistas preliminares nos moldes elaborados por Lacan. Devido ao fato de se tratar de instituição de passagem (tratamento da fase aguda) 
pareceu-nos que o dispositivo das entrevistas preliminares era o mais adequado para a oferta inicial de escuta analítica.

As entrevistas preliminares têm a mesma estrutura da análise, mas são dela distintas. Eis como as descreve Quinet:

A expressão entrevistas preliminares corresponde em Lacan ao tratamento de ensaio de Freud. Essa expressão indica que existe um limiar, uma porta de entrada na análise totalmente distinta da porta de entrada do consultório do analista. Trata-se de um tempo de trabalho prévio, à análise propriamente dita. ... Na prática depreendemos, no entanto, que nem sempre é possível demarcar nitidamente esse umbral da análise. Isto ocorre porque tanto nas entrevistas preliminares quanto na própria análise o que está em jogo é a associação livre (Quinet, 1993, p.14).

Procuramos, também, estabelecer um paralelo das entrevistas preliminares com a chamada "clínica da urgência", dada a proximidade dessa situação com a de nossos sujeitos. Segundo Soares (1996), no contexto hospitalar não podemos falar de um processo analítico, mas de uma escuta analítica que propicia a articulação significante, de modo que o sujeito possa aliviar ou se proteger da carga pulsional, transferindo-a para uma cadeia significante. Nesse momento, o trabalho de escuta busca a recuperação da ancoragem simbólica por meio da articulação significante, para então viabilizar a formulação de uma demanda e a possibilidade da clínica do inconsciente. A clínica da urgência poderia ser caracterizada como: "... un Ilamado, de carácter urgente, a una palabra que opere restituyendo un lazo discursivo que há visto interrumpido bruscamente" (Gamsie, 1998, p.20).

Portanto a pesquisa consiste de reflexão e de análise dos "dados" que decorreram do trabalho realizado junto a um grupo de toxicômanos, utilizando-se da experiência de escuta da toxicomania fundada no método psicanalítico, no quadro das entrevistas preliminares, dentro do referencial da "clínica da urgência", no contexto de uma instituição pública.

Vale reafirmar que a reflexão sobre essa prática é feita dentro do referencial teórico psicanalítico. Porém, ao contrário do psicanalista que vive a experiência da clínica e num dado momento do seu percurso, identifica uma temática importante, resolvendo refletir e produzir um conhecimento sobre ela, no caso deste pesquisador o que era tema de pesquisa virou pretexto para exercer a escuta dos sujeitos que usam droga e que poderiam ou não reincidir nesse uso, simplesmente como uma parte a mais do trabalho que já realizava na instituição com esses indivíduos. Porém a pesquisa foi apenas uma circunstância da produção dessa prática, pertinente e necessária por si mesma dentro de qualquer programa de atenção aos toxicômanos.

Não obstante, com essa inversão (fazer a pesquisa resultar de uma ação sobre uma realidade), procuramos fugir à situação mais comum na pesquisa universitária, que primeiro investiga para depois transformar, e que supõe o pesquisador como sujeito do conhecimento, cabendo ao pesquisado o lugar de objeto a ser conhecido. Também procurávamos ser coerentes com a hipótese de que nossos sujeitos eram, antes de tudo, produtores de conhecimento, detentores do saber sobre os impasse de seu gozo, e únicos capazes de produzir as saídas necessárias.

Diferenciamos, portanto, dois momentos bem distintos no processo de que faz parte a pesquisa. $O$ primeiro foi o da intercessão (intervenção), em que a palavra era dada ao sujeito e a ele cabia o protagonismo como pré-requisito para produzir o saber que dizia respeito a suas demandas psíquicas (inconscientes ou conscientes). Até aqui podíamos perfeitamente ainda não ter pensado em uma pesquisa no sentido comum do termo. Nossa relação com esses sujeitos tão pouco era de pesquisador. Entretanto registrada do melhor modo possível cada entrevista preliminar após sua ocorrência, este foi o material objeto da pesquisa e reflexão teórica: trabalho de produção de conhecimento que cabe ao pesquisador. Por outro lado, essa inversão foi absolutamente necessária para introduzirmo-nos num modo de produção de conhecimento coerente com o método de pesquisa e produção de saber fundado na psicanálise, que é o nosso referencial.

O material resultante das entrevistas foi analisado a partir da construção de categorias, segundo os princípios do método Hermenêutica-Dialética (Minayo, 2000) e do raciocínio psicanalítico (Mezan, 1998; Silva, 1993). Nessa perspectiva as categorias são resultantes do trabalho do pensamento em sua interação com os dados, portanto construções do pesquisador. 
A pesquisa foi autorizada pelo comitê de ética da instituição em que foi realizado o trabalho, depois de algumas pequenas hesitações. Tiveram dificuldade em compreender por que o consentimento só podia ser pedido no último contato com os sujeitos.

\section{Resultados e Discussão}

Na análise do material obtido nas entrevistas preliminares, e na seqüência de acompanhamento psicoterápico dos sujeitos em situação de toxicomania, operamos a partir de algumas categorias emergentes das suas próprias falas e de nosso trabalho de elaboração teórica, tentando compor uma espécie de ordenação subjetiva do conjunto dos dados dos casos (Brousse, 1989), buscando a singularidade dos sujeitos e das demandas eventuais de saírem da situação em que a relação com as drogas os colocava naquele momento. Essas categorias não são exaustivas, porém expressam o resultado de um movimento importante do trabalho de elaboração teórica, que pretende ter abarcado algumas determinações essenciais do fenômeno estudado.

Havia uma questão inicial que motivou nossa idéia da pesquisa: "possíveis fatores da reincidência na visão do adicto". Ela foi retomada na análise dos dados, porém, nesse momento, conjuntamente com todas as outras questões surgidas da situação de uma escuta psicoterapêutica dos sujeitos vivendo a experiência da toxicomania, da reincidência e da tentativa de sair delas.

\section{Eu sou dependente}

A atribuição do rótulo "eu sou dependente" (ou "eu sou adicto", "eu sou toxicômano), como traço de identidade, foi recorrente nas falas dos sujeitos. Essa auto-identificação parece estar em consonância com um imaginário que a própria sociedade criou, reproduzido através dos dispositivos de tratamento, que reforçam a postura de impotência irremediável diante do controle do uso de drogas. Como exemplo temos o discurso dos Narcóticos Anônimos (NA) e da própria psiquiatria, que ainda colocam o uso de drogas no lugar de doença incurável. Diremos que na realidade os toxicômanos permanecem congelados num discurso emprestado do "mestre social". Trata-se de um tipo de alienação ao saber do Outro. Um aprisionamento tendendo à cronificação numa identidade tautológica. É como se a nomeação "dependente" ou "drogadicto" se referisse a algo determinado geneticamente. Como se a partir do momento que esses sujeitos assumissem essa identidade, nela já estivesse incluída a posição de impotência perante a droga, e isso tornasse sua condição natural e inquestionável.

Esse discurso, além de conduzir e manter o sujeito num processo que pode incluir a desresponsabillização pelo ato de drogar-se, contribui para deixá-lo encerrado em um paradoxo subjetivo (porque sou toxicômano devo fugir da droga), e com a impressão de que a ele não cabe fazer ou dizer nada sobre isso.

Como conseqüência dessa visão determinista é comum que o tratamento se inicie por uma abstinência induzida (foi o caso dos indivíduos que participaram desta pesquisa). Verificou-se que, na situação de internação, o rótulo identitário "sou toxicômano" está ainda mais reafirmado. Pois à acentuação do impulso, devida à abstinência, somam-se a memória do gozo que retorna mais intensamente e a insegurança de imaginar-se sem o abrigo da instituição. Com isso, a explicação determinista e memória do gozo, em abstinência, parecem reafirmar-se mutuamente, contribuindo para o retorno ao uso logo no primeiro passo fora da instituição.

Apesar do esforço de conscientização realizado pelo tratamento, os indivíduos demonstram que a abstinência em que se encontram é vivida como se fosse totalmente independente do seu desejo - daí que não cheguem a identificar tais interrupções forçadas como parada do uso. Nesse caso também parece não se colocar para eles a idéia de que, no retorno às drogas após a saída da instituição, tenha havido uma reincidência. Parecem perceber a ação do tratamento de abstinência como uma parada necessária que regula seu vínculo com as drogas - uma espécie de limite externo em suplência à falta de limite subjetivo.

Identificar-se como "eu sou toxicômano", na abstinência, parece estar associado também à sensação de derrota e recaída. Torna-se um momento difícil para o sujeito, em que ele nos relata não suportar a potência do gozo da droga e suas conseqüências, mas também não poder viver sem ele. Aqui o indivíduo já expressa 
claramente como está confrontado com ideais valorizados social e subjetivamente, cuja inacessibilidade ele atribui à condição de usuário de drogas.

Por outro lado, o discurso "eu sou dependente", acentuado na abstinência, parece contrapor-se ao "eu sou eu", mais associado ao momento da experimentação, marcando o sujeito num gozo que ele diz ser o único a ter. No momento da experimentação da droga, parecem fugir, para esses sujeitos, todos os questionamentos sobre sua situação, tamanha a força atrativa que o gozo da droga oferece. Os questionamentos só retornam nos intervalos de uso e na abstinência condicionada pela internação, como era de se esperar. Por outro lado, vale assinalar que o refrão "eu sou eu" do momento do uso é só uma outra versão da mesma tautologia que tampona e dificulta a divisão subjetiva digamos que se trata, nos dois casos, de uma certeza hiperbólica e denegatória.

Na abstinência, os sujeitos querem certezas absolutas e ficam desesperados quando elas não vêm. Isso parece reforçar a única certeza que têm: "sou toxicômano", reforçando a avidez do gozo do corpo, traduzido no impulso imediatamente sentido e na memória desse gozo, e tornando-os vulneráveis ao uso quando fora da instituição. Nossos dados indicam que o trabalho da escuta analítica pode abrir espaço para um sujeito dialetizador, ao permitir falar de muitas coisas, inclusive da droga, abrindo a subjetividade para o saber inconsciente a ser produzido e, por hipótese, oferecendo oportunidades de cifrar o gozo. Percebemos que isso pode ocorrer a partir das entrevistas preliminares. Várias ocorrências no trabalho realizado a partir da oferta de escuta psíquica aos toxicômanos dão indicações inequívocas, embora suas circunstâncias objetivas não tenham sido as mais favoráveis (instituição de passagem, um programa terapêutico de feições marcadamente médicas e pedagógicas). Adiante analisaremos alguns aspectos dessa função de abertura subjetiva da escuta psicoterapêutica fundada na psicanálise.

\section{Valores fálicos: nostalgia e conflito}

O uso das drogas parece claramente contraposto, para a maioria dos sujeitos deste estudo, a exigências sociais e subjetivamente valorizadas, que são vividas como negligenciadas ou deixadas para trás em virtude da toxicomania. A nostalgia desses valores fálicos também tende a acentuar-se no momento da abstinência; trata-se de valores ligados a "ideais de ser" bom pai de família, bom trabalhador, bom filho. Suas falas demonstraram intensas aspirações voltadas para valores como o prestígio e o respeito sociais e familiares.

No conjunto geral das entrevistas, porém, ao lado dessa situação em que os sujeitos manifestam conflito entre a opção pelos valores fálicos e pelo gozo da droga, encontramos o que pareceu outra tendência: alguns indivíduos em que a referência a esses valores é mais remota, deflagrando-se mais abertamente uma inclinação para o gozo da droga. Esses achados permitem avançar teoricamente e supor duas tendências, dividindo o conjunto de sujeitos da nossa amostra quanto à função psíquica desempenhada pela toxicomania, detectável através de sutilezas surgidas nas entrevistas.

Dos onze entrevistados, oito parecem utilizar a droga para viabilizar a fantasia necessária à sua entrada no mundo cotidiano, ou seja, ela é meio para um gozo narcísico comum, ainda que de intensidade acentuada: atenuação superegóica, engrandecimento da auto-imagem, melhora imediata da potência (Melman, 1992). Nesse subgrupo, os sujeitos parecem apresentar a nostalgia dos valores fálicos, mas paralelamente ficam sensíveis à nostalgia da vivência de completude propiciada pelo gozo associado às drogas. $\bigcirc$ gozo obtido com as drogas, nesses casos, parece estar associado também à onipotência narcísica que os poria como objetos privilegiados do olhar do outro. Pode-se propor a hipótese de que esses indivíduos estão estruturados do modo psíquico que antes associamos à constituição por recalcamento. Neles aparece a aspiração ao uso controlado das drogas, tal como observado nos alcoolistas, sem prejuízo, e mesmo a serviço, do gozo fálico. Para eles o paroxismo do gozo que caracteriza o momento toxicomaníaco parece ser apenas um acidente, que a instituição é chamada a corrigir.

Os outros três indivíduos ou não demonstram uma nostalgia dos valores fálicos, ou falam disso superficialmente. A droga parece funcionar como fuga da realidade, mas, sobretudo, fuga para outra realidade. Neles o que aparece é um horror da realidade e não um conflito do gozo da droga em paralelo a um desejo de viabilizar os valores fálicos, como nos demais sujeitos da pesquisa. Essa segunda modalidade parece mais 
próxima daquilo que, a partir da teoria da teoria psicanalítica, podemos definir como toxicômano propriamente dito. Nesses, a aspiração a um gozo todo, que a psicanálise conceitua como gozo do corpo, parece a aspiração mais radical. Seria o tipo psíquico que antes associamos à constituição por renegação (classicamente chamado perverso).

Parece-nos que essas hipóteses, embora preliminares, e produzidas com dados relativamente restritos, merecem aprofundamento em futuros estudos, visando contribuir para a melhor compreensão do problema e para o aperfeiçoamento dos dispositivos de atenção propostos pelo Ministério da Saúde (CAPSad) (Ministério da Saúde, 2001, 2004).

\section{Abstinência e culpa: um traço comum?}

Ao falarem da culpa por não atingirem os valores fálicos, os sujeitos indicam que ela aparece reforçada pela situação de abstinência prolongada e pelo próprio programa da instituição. As observações do funcionamento institucional evidenciaram que nesse tempo da internação, dado o caráter pedagógico das ações, os indivíduos são expostos a um discurso que procura lembrar a todo o momento sua situação de "dependente químico", e de como suas perdas decorrem da situação de usuário de drogas. Percebemos, portanto, que embora a culpa seja um elemento passível de surgir na situação de abstinência - dado tratar-se de um conjunto de indivíduos em cuja maioria (oito) os componentes narcisistas são predominantes, conforme vimos anteriormente. Nas condições do pedido inicial de ajuda à instituição, a maioria parece se referir menos à angústia do ciclo gozo-abstinência ${ }^{5}$, e mais aos inconvenientes da toxicomania, que indispõem à aquisição dos valores sociais comuns, índices da aprovação narcísica de que parecem ser ávidos.

Podemos dizer, então, que no conjunto dos sujeitos ouvidos a culpa está presente, mas de modo pouco intenso. Nos indivíduos narcísicos, associada à frustração de expectativas próprias e dos outros. Nos indivíduos cuja hipótese de constituição parece ser o modo da renegação, não foi detectada a culpa associada ao ciclo uso-abstinência, o que era esperado. Apenas algumas atitudes radicais tomadas para conseguir a droga no momento da extrema avidez parecem gerar culpa (como roubar parentes próximos).

Tanto os dados dos sujeitos escutados analiticamente quanto nossas observações nas outras atividades do programa terapêutico da instituição de que participamos indicam que quando os sujeitos falam em culpa, eles a nos permitirem supor tratar-se de um discurso racionalizador, devido muito provavelmente ao contexto da internação ou das condições "impostas" para continuidade do tratamento (abstinência necessária). Durante a internação e, portanto, fora do gozo do corpo, os sujeitos indicam reconhecer sua condição de toxicômanos, reforçados pela desintoxicação e pelas exigências do discurso da abstinência. Cumprida essa tarefa, parecem não querer se recordar do passado, preferindo partir para uma tentativa efetiva, ou meramente alusiva, de dedicar-se à "mentira" das promessas de alcançar, desta vez, os valores fálicos que até então não conseguiram atingir. Os seus discursos são, na maioria das vezes, para apagar magicamente a dor produzida pelo passado. É como se, retirando a droga pela abstinência, eles acreditassem no nascer de um novo sujeito, em concordância com os valores cobrados pela sociedade e com o modelo de trata-mento fundado no princípio doença-cura da instituição. Para eles a tarefa maior da internação parece ser livrar-se das conseqüências imediatas desagradáveis associadas ao momento que se sucede à queda no ciclo de dependência do gozo do corpo que caracteriza a toxicomania. Ou seja, mitigar a angústia vivenciada nos intervalos de uso e associada às conseqüências do uso refletidas no ambiente familiar é um modo de se restabelecer para poder retomar a trajetória do uso.

Os dados também parecem indicativos de que a oferta de escuta analítica, quando aceita, é capaz de contribuir para outros desfechos dessa "oportunidade" que os indivíduos se dão ao recorrerem de novo a um tratamento a cada momento de maior crise.

\section{A família no discurso e na realidade}

Chama a atenção que a abordagem da família como componente do processo de tratamento não seja

\footnotetext{
5 O ciclo gozo-abstinência se caracteriza pela oscilação do indivíduo entre posições de extrema felicidade (uso) e extrema angústia (intervalos do uso). Essa angústia pare associar-se a sentimentos de culpa, quando se trata de subjetividades cuja hipótese de constituição é o recalcamento (Sissa, 1999).
} 
mencionada pelos sujeitos. Mas os entrevistados destacam sempre a situação familiar e sua relação com a família, em alguns casos, marcada por sentimentos ambíguos. A família aparece tanto como protetora e continente quanto contribuindo para a causa do uso de drogas, porém é, em todo o caso, um aspecto muito valorizado, estando de acordo com o cultivo dos valores fálicos pela maioria dos indivíduos entrevistados. Embora a presença da família, na fala dos sujeitos, pareça mais claramente associada aos que cultivam esses valores (constituição por recalcamento), nossos dados não permitem afirmar a situação dos outros indivíduos (constituições por renegação) a respeito da relação com a família. Também aqui está um aspecto que merece continuar sendo escutado a fim de trazer conhecimento para melhor situarmos a família nos projetos de atenção à toxicomania.

\section{O caráter mítico do gozo do corpo e suas funções na subjetividade}

O caráter repetitivo do gozo foi outra constante mencionada por nossos sujeitos, na situação da toxicomania. Como vimos anteriormente, é próprio ao gozo do corpo a exigência da recorrência do ato de se drogar. Essa repetição aparece referida a uma suposta memória da primeira experiência de satisfação com a droga. Daí que alguns sujeitos relatem ficar em busca do primeiro gozo, ou seja, da sensação do primeiro uso, que, entretanto, nunca mais encontram. Isso os faz aumentarem a dose e a diminuírem os intervalos de não-uso, contribuindo para o rápido estabelecimento da toxicomania. A rememoração através da repetição acentua, no gozo do corpo, seu caráter mítico. Isso significa dizer que o gozo do corpo é algo postulado, como tendo existido, apenas a posteriori, sendo um dos efeitos da inscrição do corpo no simbólico.

O toxicômano é um sujeito que se aferra à idéia desse gozo mítico, desde sempre e para sempre impossível, tentando resgatá-lo na experiência com a droga. Assim, pode-se postular a hipótese de que os toxicômanos, na situação de tratamento, resistem a entrar na relação com o gozo fálico como solução estabilizada, em parte pela força sedutora do gozo do corpo, que lembra um gozo mítico inesquecível, e em parte devido a sua forma particular de inscrição no campo do simbólico que produz em certo empuxo a uma relação objetal que faz curto-circuito da linguagem como instância terceira de regulagem e temperança.

Também aqui é necessário nos referirmos a dois modos de relação ao gozo do corpo: um que se apresenta como contingente, o outro como necessário. Para os últimos nos referimos, anteriormente, ao encontro entre a experiência da droga e uma memória remota corporal de gozo que é reativada como tal (traços mnêmicos de coisa), no quadro de uma constituição por renegação. Para os outros, temos associado esse gozo a traços acentuados de narcisismo na conjuntura subjetiva do recalcamento. É para os últimos que os dados da escuta analítica parecem indicar as perspectivas mais imediatas e consistentes de abertura subjetiva.

Na relação facultativa com o gozo, o uso da droga é interrompido à mercê de certos acontecimentos, não necessariamente fatores como a angústia no estado avançado da toxicomania ou o processo de tratamento. A interrupção do uso se dá pelas vicissitudes próprias da vida do sujeito, por exemplo, a presença da mulher na relação amorosa parece funcionar como um apaziguador do gozo. Isto é mais um elemento que leva a pensar o estatuto da toxicomania para esses indivíduos. O gozo do corpo não parece ser organizador central da vida subjetiva desses indivíduos, o que, por hipótese, os deixaria mais suscetíveis à abertura subjetiva na situação do tratamento.

Nos outros casos, em que a relação com o gozo parece necessária, apenas a abstinência forçada é capaz de tamponar uma fissura que se faz constante. É como se nos intervalos de uso houvesse uma tampa permitindo que a droga ficasse ausente, de modo que na primeira oportunidade que o sujeito permita que a tampa saia o ciclo de uso recomeça. Nesses sujeitos as paradas só acontecem forçadamente, por exemplo, numa internação. Neles a abertura subjetiva parece mais difícil porque os sujeitos revelam não se interessar por outros gozos além do oferecido pela droga. Nossos dados ainda não favorecem uma boa análise dessa situação, sendo necessárias outras pesquisas. 


\section{Frustração e impulsividade: soluções em curto-circuito}

O baixo limiar à frustração aparece como uma característica marcante da psicologia desses indivíduos e parece ser uma condição importante para que o suposto tamponamento operado pela química seja facilmente desfeito. Entretanto os acontecimentos apontados como disparadores, nos momentos de retomada do uso ou de sua exacerbação, poderiam ser caracterizados mais como pretextos do que propriamente como motivos, uma vez que defendemos a hipótese de que a química só opera como tamponamento, e não como mudança de posição subjetiva. Ou seja, os retornos ao uso dependeram, sobretudo, de disposições subjetivas que o tratamento baseado na desintoxicação e abstinência deixou intocadas, sejam as situações de frustração e impulsividade relacionadas às modalidades subjetivas narcísicas, sejam as situações de compulsão relacionadas à modalidade de afeição ao gozo do corpo. A frustração e a impulsividade claramente presentes em todos os indivíduos também podem ser relacionadas a duas modalidades da constituição subjetiva, quanto a sua intensidade.

Os dados revelam que os sujeitos, na busca do gozo do corpo, tendem a fazer curto-circuito da intermediação simbólica, que supõe a possibilidade da espera. O prejuízo dessa intermediação, em maior ou menor grau, parece interferir diretamente na tolerância à frustração, fazendo com que o sujeito recorra à droga como solução radical ilusoriamente estabilizadora diante de uma angústia vivida como inexplicável, associada aos mais diferentes impasses cotidianos.

\section{Abertura subjetiva num contexto adverso} is anterior ao novo discurso, e parecem colocar o usuário de drogas no isolamento, como garantia do controle da abstinência através da internação. A apa- rente desconfiança dos sujeitos não parece ser por acaso, porque estar internado já reforça o estigma de "fracassado" no que tange a cuidar da sua vida. A grande maioria das atividades realizadas na instituição reforçava o fracasso dos sujeitos, dando sustentação ao clichê "sou dependente". A abstinência vivida como tratamento aumenta a dificuldade de abertura subjetiva, quando se introduz a possibilidade da escuta.

É necessário retomar que o NADeQ está caracterizado dentro de uma ótica inclusive hospitalar. A internação parece servir para que o sujeito dê uma pausa no gozo que a droga produz. Essa instituição não constitui uma exceção às demais com a mesma função quanto às possibilidades de escuta analítica. Por outro lado, os dados da escuta nos indicam que, muitas vezes, os indivíduos não têm porque parar. Querem livrar-se apenas dos inconvenientes da situação de crise.

Se podemos dizer que eles chegam a ter condições de problematizar sua toxicomania, é no período da internação. Entretanto os dados nos indicam que o tratamento baseado no tamponamento tem como resultado mais provável o retorno à situação de experimentação do gozo a que são aficionados, isentos do desejo de livrar-se dele. Por outro lado, nossa experiência demonstra que a internação também pode ser a oportunidade que o sujeito se dá de alguma abertura subjetiva, contanto que se possa fazer ofertas compatíveis de possibilidades transferenciais nessa direção. O sujeito que pede ajuda dizendo estar "no fundo do poço", por exemplo, apresenta, mesmo que de forma paradoxal, uma manifestação do sujeito do inconsciente: sou um objeto caído.

A psicanálise, mesmo em sua aplicação ao contexto hospitalar, postula a possibilidade da transferência como função da oferta de escuta e não o contrário. E uma escuta só pode ter sucesso se produzir algo diferente daquilo que pode ser produzido pelo tamponamento. Se permitir ao sujeito chegar a se dividir, produzindo questionamentos do tipo "será que não sou outra coisa que toxicômano?". O conhecimento psicanalítico da problemática desses indivíduos permite afirmar que se não for feito algo, logo a partir do início do seu pedido de ajuda, para que um sujeito desejante apareça, muito provavelmente o tamponamento propiciado pela abstinência se desfará na primeira oportunidade que o indivíduo tiver para gozar 
novamente: é também o que os achados nos indicam inequivocamente. O espaço de escuta deve afastar-se do lugar de confessionário, prestação de "contas" ou mesmo de produção de "roteiros de cura".

Nossa tentativa de realização desta proposta de escuta dos toxicômanos não foi fácil. Aos entraves institucionais já assinalados somaram-se suas características subjetivas. Os sujeitos ora ocupam a posição de doentes e solicitam respostas imediatistas de quem os escuta ou se mostram detentores do saber de um gozo privilegiado somente experimentado por eles, a respeito do qual também não demonstram muito interesse em falar.

Se acrescentarmos à visão da toxicomania alguns pressupostos evidenciados neste estudo, talvez seja pertinente uma proposta de revisão de alguns dos saberes atuais que reforçam a ênfase numa terapêutica médica, deixando em segundo plano as outras formas de abordagem da questão. O saber psiquiátrico tem sua função, mas reforçar o discurso medicamentoso e sua prática, aliviando radicalmente o sofrimento do sujeito na abstinência, pode reforçar a ambigüidade do sujeito e dificultar a proposta de uma escuta que vise à aproximação do indivíduo à sua história e à relação com o uso de drogas. Não esqueçamos que, saídos da internação, os sujeitos são encaminhados para uma seqüência de tratamento ambulatorial que tem como possibilidade a oferta de psicoterapia.

Nesse sentido nos questionamos se os sujeitos são ou não lacônicos como parecem demonstrar nos primeiros momentos do contato. Eles falam pouco sobre o uso da droga porque o gozo não está intermediado pela linguagem, ou porque o discurso institucional restringe o espaço, através da abstinência e da medicação como formas principais do tratamento, provocando uma inibição para as práticas discursivas?

Talvez os sujeitos possam ser lacônicos porque o discurso dominante opera em torno do objeto droga que a princípio não faz falar, e sim faz gozar, criando condições ótimas para extirpar o aparecimento do sujeito do inconsciente. Por outro lado, o fato de estarem internados, e conseqüentemente privados da droga no momento das entrevistas, pode sustentar o imaginário da "proibição" de falar das delícias desse gozo. Entretanto os sujeitos falam de muitas coisas para além da droga, coisas que fatalmente levam ao encontro com suas questões subjetivas centrais nas quais a droga está incluída.

Assim é preciso considerar que os entrevistados estão dentro do hospital e no contexto da saúde coletiva. Os sujeitos parecem ter da instituição a percepção como aquela que medica e propõe o tratamento através da desintoxicação e abstinência na internação. A ação do psicoterapeuta, que na representação social ocuparia o lugar de quem escuta, tem dificuldades de se distinguir da ação do hospital, que oferta o remédio na desintoxicação e reitera a manutenção da abstinência.

Dada uma situação institucional desse tipo é preciso muita persistência e alguma experiência na ocupação do lugar do psicoterapeuta para poder interferir na forma inicial da transferência desses sujeitos e operar na transformação da sua identidade de "dependentes". É necessário também que a instituição se abra para as dimensões mais complexas da questão.

\section{Abstinência e reincidência}

O objetivo inicial que motivou este trabalho era a investigação dos fatores da reincidência na toxicomania, do ponto de vista do toxicômano. Porém a realidade da toxicomania, a teoria da psicanálise e o método psicanalítico de pesquisa nos permitiram a abertura para a possibilidade de investigar e analisar também outras questões mais amplas sobre o tema. De tal modo que a reincidência foi considerada como uma questão entre outras presentes nos discursos dos toxicômanos, quando escutados livremente no contorno das entrevistas preliminares em psicanálise.

Ao final de nosso percurso de investigação, respaldados pelas considerações teóricas e pela própria escuta que se suporta na teoria psicanalítica, a reincidência inicialmente definida pôde ser reescrita em outras palavras: o momento em que o sujeito, após ter feito uma renúncia ao gozo do corpo, renúncia que o leve à extinção do ritual de experimentação reiterada, volta, posteriormente, essa mesma modalidade de gozo, retornando ao descontrole e à exclusividade que este oferece, desencadeando um novo pedido de internação.

Os pontos até aqui discutidos nos fornecem pistas fecundas para aprofundar a análise da reincidência. Ela aparece como um falso problema. Para os sujeitos o 
movimento de paradas e voltas não é percebido como reincidência, pois quando estavam na abstinência não consideravam que estavam fora da droga. Indicaram que a abstinência resultante da desintoxicação, concomitante à abstinência provocada pela internação, é somente um momento transitório de privação do gozo do corpo. Não significa que os sujeitos faziam uma renúncia que caracterizasse o desejo de distanciamento da droga, mas apenas uma parada ligada às conseqüências negativas provocadas pelo gozo.

Percebemos que neste primeiro momento da escuta os sujeitos parecem ficar relativamente silenciosos a respeito de possíveis fatores da reincidência, embora apontem indiretamente aspectos associados à retomada do uso. Também não se referem aos "métodos" utilizados no tratamento, nem há menção à importância à sua importância. Para eles o termo tratamento parece estabelecer ligação com o discurso da abstinência. 0 distanciamento do gozo do corpo parece resultar em sinônimo de tratamento. Em síntese, os sujeitos escutados deixam entrever com certa clareza que sua relação com as drogas é um contínuo, às vezes interrompido temporariamente, tanto por situações comuns da vida, quanto por momentos agonísticos relacionados com a toxicomania. A partir do tratamento padrão oferecido pela instituição, não percebemos, entre os entrevistados, casos que tenham postulado um desejo perseverante de interrupção do uso. Enfim, a forma da reincidência encontrada foi bem diferente da previamente vislumbrada no início da pesquisa.

As políticas de saúde podem estar tentando se deslocar do discurso da abstinência, mas ainda reiteram o abandono da droga como ato prévio. Os dispositivos funcionam segundo o discurso médico, priorizando a abstinência, sem a preocupação de "modular" o gozo para que o sujeito fique aberto a outras formas de abordagem que não a medicamentosa. Além disso, as entrevistas e o contato cotidiano com os usuários do serviço demonstraram o caráter intersetorial das toxicomanias. Por isso não parece indicado remetê-las ao tratamento ligado somente a instituições de saúde. E mesmo no segmento que pode ser de incumbência dessas instituições é urgente fazer valer na prática o discurso da interdisciplinaridade.

Se não for aproveitado o momento da internação para produzir a abertura do discurso desses sujeitos no 500 período pós-alta, muito provavelmente terão se esvaído, para eles, as questões a trabalhar, não vendo sentido para retornarem aos seus atendimentos. Do modo como se está trabalhando, com base no esquema internação-abstinência-alta, podemos estar alimentando o imaginário de que, no intoxicado, não há dimensão subjetiva a ser trabalhada; e uma vez fora da intoxicação, tendo retomado o uso, não há mais espaço para ele no contexto institucional. Muito provavelmente os sujeitos só voltarão a procurar a instituição quando as condições de vida se tornarem de novo insuportáveis, o que recairá num novo pedido por internação, fechando, assim, o ciclo intoxicação-internação-abstinência-intoxicação.

\section{Considerações Finais}

O presente trabalho explorou o fenômeno da toxicomania num momento em que o setor da saúde permanece muito solitário, ensaiando seus primeiros passos no estabelecimento de parcerias com outros setores da sociedade, tais como polícia, justiça, educação, assistência social, habitação, cultura e coletividade, para o equacionamento da questão. Nessa síntese final tentaremos produzir mais alguns questionamentos e arriscar algumas considerações teóricas, além daquelas que já foram enunciadas ao longo do trabalho.

1. Se o gozo da droga é tão sedutor, desejado e bom, por que aparece como assustador ao mesmo tempo? Por que os sujeitos se abrigariam de um gozo tão prazeroso, pedindo uma internação? Podemos vislumbrar que, mesmo sedutor, desejado e bom esse gozo também pode ser assustador justamente devido à possibilidade de empurrar o sujeito para as proximidades da morte. Nosso estudo deu indicações de que o gozo da droga é simultaneamente amado e temido. Naturalmente trata-se do encontro com um gozo além do princípio do prazer. Nossa compreensão dos dados nos permitiu avançar na hipótese de que há, na nossa amostra, duas modalidades de toxicomania, portanto duas modalidades de relação com o gozo, diferenciadas pela configuração da subjetividade em que ocorrem: recalcamento ou renegação. Todos os pedidos de internação estiveram ligados aos inconvenientes do gozo, porém o modo desse gozo parecia mais ou menos intenso, dependendo dessa variação subjetiva.

2. Em vez da culpa - na abstinência - não poderia surgir a procura violenta da droga? Poderia. Mas para esses indivíduos o embate com o gozo da toxicomania 
parece ter um limite nomeado por eles de "fundo do poço". Chegamos a nos perguntar se não constituirão eles um subgrupo particular de toxicômanos "selecionados" pelo fato de estarem numa instituição médica cuja estratégia de tratamento se funda no princípio doença-cura (abstinência)? Os indivíduos que recorrem à instituição parecem ser aqueles que têm uma tolerância menor ao ciclo do gozo da droga, a internação não significando para eles o desejo de abandoná-la, mas apenas de viabilizar um intervalo temporário que faculte a continuidade do uso.

3. Nos perguntamos sobre a existência de fantasias mediando a relação com a droga. Algumas entrevistas evidenciam a existência de fantasias como onipotência e amor narcísico, enquanto outras falam de um gozo diretamente na carne. As fantasias aparecem no subgrupo para o qual a droga parece ser mais um meio do que um fim em si. Por outro lado, por se tratar de um gozo que faz curto circuito do significante e do simbólico, o gozo da droga exige sua repetição com ou sem fantasia. Vale a pena assinalar que a fantasia nestes casos parece funcionar mais como um moderador do gozo toxicomaníaco do que com as funções que the cabem, por exemplo, no fetichismo.

4. Como seria pensar um tratamento que não partisse da premissa da abstinência? A escuta analítica aliada à inserção do indivíduo nas ações de uma rede intersetorial e apoiada no recurso da medicação como suporte poderia ser uma boa estratégia. Atuar segundo a crença de que tirando a droga o sujeito volta a funcionar no registro do gozo fálico pode ser absurdo, porque a abstinência forçada acentua o funcionamento no registro do gozo do corpo. Se na toxicomania a relação de objeto foi deslocada para o registro da necessidade, quanto mais abstinência, maior a avidez.

Como seria tratar o sujeito intoxicado? A princípio, essa se mostrou uma hipótese plausível, pois o sujeito não está fora de si, podendo falar da sua situação e desse gozo ao mesmo tempo desejado e temido. Poder escutar o sujeito intoxicado é, ao contrário de priorizar a desintoxicação, entender que o tratamento pode ser construído em etapas. Porém há uma série de indicações de que se deve escutar desde o primeiro momento, em paralelo aos eventos da crise e da situação de internação, se esta ocorrer, uma vez que fora da perspectiva da abstinência a internação pode não ser necessária. Também suspender, de imediato, o ato da abstinência não impede de colocá-la como uma opção na meta final.

O material clínico de que dispomos, embora não possa contextualizar as toxicomanias na sua complexidade, nem na extensão de sua variabilidade, revelou a presença, no conjunto amplo dos toxicômanos, de um importantíssimo grupo de pessoas mais sensíveis à potência do gozo da droga, e que chegam à instituição para pedir um "barramento"temporário desse gozo por meio de uma internação. Talvez pudéssemos deixar aqui a hipótese de que a instituição, tal como está estruturada no momento, está perfeitamente incluída na lógica de funcionamento psíquico desses sujeitos, e que eles já parecem contar com a existência desse recurso.

5. Uma das idéias iniciais da pesquisa era explorar o fenômeno da reincidência, porém no trabalho de escuta os participantes falaram também de outras coisas, contribuindo com muitas informações e questões para a reflexão sobre práticas de atenção ao toxicômano. Seria ingênuo pensar que o sujeito numa abstinência forçada tenha trabalhado suas questões, se é que chegou a produzi-las. Nos resultados apresentados por esse procedimento nota-se apenas o distanciamento momentâneo da droga, e uma tendência futura à retomada do uso. Por outro lado, nossa intercessão revelou que a internação pode ser um momento propício para iniciar a mobilização do sujeito a exercitar sua relação com a linguagem e o desejo. Mas isso exigiu condições que viabilizassem a possibilidade da psicanálise dentro da instituição e no tempo curto da internação. Daí a necessidade que tivemos de introduzir os conceitos de "clínica da urgência" e de "entrevistas preliminares" como dispositivos apropriados para a abordagem dos sujeitos em momento e contexto específicos.

6. Vale a pena enfatizar que procuramos não cair em posturas dogmáticas nesta reflexão, abrindo-nos para a diversidade e especificidade de nossos dados. Temos a hipótese de dois modos básicos de constituição subjetiva em nossos sujeitos: há toxicomania em constituições subjetivas por recalcamento em que se evidenciam demandas de reconhecimento narcísico, associadas à nostalgia dos valores fálicos, para os quais as drogas parecem ter sua maior função como meio para esses fins de auto-engrandecimento e de aplacamento da crítica do supereu. Há também toxicomanias em constituições subjetivas moduladas por renegação. A 
estas aparecem associadas as mais renitentes identidades tautológicas e as demandas de repetição do mesmo gozo do corpo, correlacionadas com o objeto como real, ou seja, aí persiste o gozo da droga por si mesmo. Essas especificações, embora merecedoras de mais investigação, podem ter profundas implicações no tratamento.

7. Concluiu-se também que a desinstitucionalização dos toxicômanos teria que partir da possibilidade de sua circulação por outros lugares provocadores de outras identificações diferenciadas da afirmação corrente e auto-assumida: "sou dependente". Em paralelo a essa estratégia é pertinente introduzir e realizar práticas no sentido da intersetorialidade, procurando atingir o imaginário social para uma efetiva transformação da representação social do problema e das possibilidades de seu tratamento.

8. Finalmente não podemos deixar de mencionar algo que também permeou nossas considerações teóricas iniciais e foi considerado no momento da pesquisa. A toxicomania, ainda mais do que as outras problemáticas psíquicas, mantém um certo caráter de objeção aos rumos assumidos pela formação social em sua feição neoliberal globalizada (Melman, 1992). Não se poderia pretender jamais esgotar tal caráter, em qualquer modalidade de ação setorial ou intersetorial, por melhor arquitetada e politicamente correta que fosse. Ou seja, temos que escapar à ingenuidade que vê a deriva das relações com o gozo, neste momento histórico, como uma condição privada dos sujeitos. Não é demais sublinhar que esta consideração permeia e dimensiona toda a nossa análise da toxicomania.

\section{Referências}

Batista, M., \& Inen, C. (Orgs.). (1997). Toxicomanias:abordagem multidisciplinar. Rio de Janeiro: NEPAID/UERJ - Sete Letras.

Beneti, A. (1998). Toxicomania e suplência. In L. Bentes \& R. F. Gomes. O brilho da infelicidade. Rio de Janeiro: Contracapa Livraria.

Bentes, L., \& Gomes, R. F. (Orgs.). (1998). Obrilho da infelicidade. Rio de Janeiro: Kalimeros.

Brousse, M. H. (1989). O destino do sintoma. In M. B. Motta (Org.), Clínica Lacaniana: casos clínicos do campo freudiano. Rio de Janeiro: Jorge Zahar.

BYCK, R. (1989). Freud e a cocaína. Rio de Janeiro: Espaço e Tempo.

Freud, S. (1915). La represion. Obras Completas. Tomo II. 502
Freud, S. (1927). El fetichismo. Obras Completas. Tomo II. Madrid, s/d. Biblioteca Nueva.

Gamsie, S. (1998). La urgencia de intervenir. Psicoanalisis y el hospital. Buenos Aires: V. 13.

Gurfinkel, D. (1995). A pulsão e seu objeto-droga: estudo psicanalítico sobre a toxicomania. Petrópolis: Vozes.

Lacan, J. (1985). O seminário livro 3: as psicoses. Rio de Janeiro: Jorge Zahar.

Laurent, E. (1995). Versões da clínica psicanalítica. Rio de Janeiro: Jorge Zahar.

Lima, C. R. (1998). Uma passagem clandestina. In L. Bentes \& R. F. Gomes. O brilho da infelicidade. Rio de Janeiro: Contracapa Livraria.

Mariz, C. L. (1994). Libertação e ética. Uma análise do discurso de pentecostais que se recuperaram do alcoolismo. In A. Antoniazzi. Nem anjos nem demônios: interpretação sociológicas do pentecostalismo. Petrópolis: Vozes.

Melman, C. H. (1992). Alcoolismo, delinqüencia, toxicomania: uma outra forma de gozar. São Paulo: Escuta.

Mezan, R. (1998). Escrever a clínica. São Paulo: Casa do Psicólogo.

MINAYIO, M. C. S. (2000). O desafio do conhecimento:pesquisa qualitativa em saúde. São Paulo: Hucitec.

Ministério da Saúde. (2001). Manual de redução de danos. Brasília: Ministério da Saúde.

Ministério da Saúde. (2004). Política do Ministério da Saúde para atenção integral a usuários de álcool e outras drogas (2a. ed.). Brasília: Ministério da Saúde.

Nogueira Filho, D. M. (1999). Toxicomanias. São Paulo: Editora Escuta.

Olievenstein, C. (org.). (1989). A clínica do toxicômano: a falta da falta. Porto Alegre: Artes Médicas.

Passos, S. R. L. (1998). Adesão ao tratamento ambulatorial para dependência de drogas. In L. Bentes \& R. F. Gomes (Orgs), O brilho da infelicidade. Rio de Janeiro: Contracapa Livraria.

Quinet, A. (1993). As 4+1 condições da análise. Rio de Janeiro: Jorge Zahar.

Santiago, J. (2001). A droga do toxicônano: uma parceria cínica na era da ciência. Rio de Janeiro: Jorge Zahar.

Silva, M. E. L. (Coord.). (1993). Investigação e psicanálise. Campinas: Papirus.

Sissa, G. (1999) O prazer e o mal: filosofía da droga. Rio de Janeiro: Civilização Brasileira.

Soares, C. P. (1996). Uma tentativa malograda de atendimento em um centro de tratamento intensivo. In M. D. Moura (Org.), Psicanálise e hospital. Rio de Janeiro: Revinter.

Souza, A. (2003). Os discursos na psicanálise. Rio de Janeiro: Companhia de Freud.

Valas, P. (2001). As dimensões do gozo. Rio de Janeiro: Jorge Zahar.

Recebido em: 2/5/2006

Versão final reapresentada em: 29/8/2006

Aprovado em: 24/4/2007 